Pupils' challenges and coping mechanism in the implementation of distance learning modality and its relation to their performance at Bagong Pag-asa Elementary School

Garcia, Ma. Glaiza $\bowtie$

Emilio Aguinaldo College, Philippines (maglaiza.garcia@deped.gov.ph)

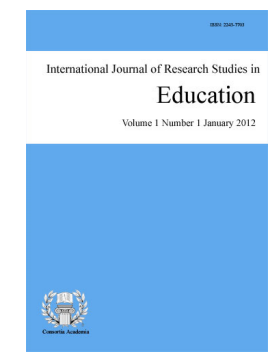

ISSN: 2243-7703 Online ISSN: 2243-7711

OPEN ACCESS

\title{
Abstract
}

This study aimed to determine the relationship between the extent of challenges and coping mechanism in the implementation of distance learning modality and the performance of Grade 5 pupils at Bagong Pag-Asa Elementary School during the school year 2020-2021. The respondents of the study were the forty-five Grade Five pupils who are enrolled in the distance learning modality. Descriptive correlation was also used to determine the relationship between the extent of challenges in implementing distance learning modality and the performance of Grade 5 pupils. More so, the researchers utilized the researcher-made instrument. The study found out that the pupils are highly challenged in implementing modular learning modality with an overall mean of 3.51 regarding individual and school-related challenges. And they are also challenged in terms of related instructional challenges wherein the pupils are having difficulty understanding the instruction in the module due to lack of communication. It implies that pupils have difficulty in understanding the instructions from their teachers. However, the majority of the learners obtained a Fairly Satisfactory rating. No significant relationship between the level of pupils' challenges in implementing modular learning modality and the performance of Grade 5 pupils as revealed by their average grade in the first quarter. It simply implies that pupils' challenges in implementing modular learning modalities did not significantly correlate to their performance. According to the pupils, their coping mechanism in the implementation of modular learning modality is the following: Boosting self-confidence by encouraging each other; positive outlook in addressing the challenges in the new normal; time management is a must to accomplish the activities on time; prioritizing in answering the learning activities even late at night; openness to change, and to seek help and assistance from their teachers and classmates.

Keywords: challenges, coping mechanism, distance learning, modality, performance 


\section{Pupils' challenges and coping mechanism in the implementation of distance learning modality and its relation to their performance at Bagong Pag-asa Elementary School}

\section{Introduction}

One of the emerging global emergencies in public health is the COVID-19 pandemic caused by a Novel Coronavirus SARS-COV-2. Infection control and physical distancing measures are crucial to prevent the virus from further spreading and to help control the pandemic situation. The policy of compulsory physical distancing has been implemented in many countries, including the Philippines, resulting in nationwide school and institution closures. Therefore, educational institutions had to adopt a digital approach to instruction and student learning, dramatically transitioning traditional face-to-face classroom instruction to predominantly distance learning. Teaching is provided remotely on digital platforms, printed modular, mobile education, or online learning.

Similarly, DepEd sets a distance learning approach that utilizes three methods: the delivery of printed modules to the learners; access to DepED commons, an online education platform DepEd developed to support alternative modes of learning; and delivery of lessons or self-learning modules via radio and television. They also address the challenges through the Learning Continuity Plan, which includes key features on K-12 curriculum adjustments, alignment of learning materials; various modalities of delivery; and corresponding teacher and parent/guardian training for homeschooling. These modifications on certain policies and practices were necessary steps in adapting to the "new normal" while remaining true to the framework of Sulong EduKalidad and Education Futures. In addition, the integration of alternative modes of learning will surely help the government. Specifically, the Department of Education ensures the learners' quality of education must receive this current school year 2020 2021.

According to Douglas (2020), no matter how well designed a course is, students will not learn unless they put a reasonable effort into the learning process. A problem for many students and educators is in determining exactly what a reasonable amount of effort is. In addition, De Villa (2020) said that since education is believed to continue despite the circumstances, teachers started to prepare for modular and online distance learning. Teaching is possible, but has challenges as well. Findings revealed that as education migrates to a New Normal, teachers make necessary preparations to equip themselves with distance learning.

Though they face challenges that may hamper their work, they still manage to cope with the new normal to continue their tasks. Therefore, the higher offices and school authorities should work with teachers at the pre-implementation of distance learning to address their needs in resources and training to effectively facilitate quality education for students.

The new school year comes with new modes of learning, a new normal in education established as a precaution against this health crisis. Unfortunately, this new normal has affected and will continue to affect millions of learners, teachers, and non-teaching staff worldwide. Whatever mode of flexible learning at school may implement, teachers and administrators are undoubtedly concerned with maintaining learner engagement. However, many challenges come into the educational system. First, it can be in the administrative section wherein some learning modes are conducted without a teacher or facilitator. As a result, learners may get confused about how they could progress through the course, especially if they are not aware of the expected activities or desired outcome. Second, administrators can expect their students to feel isolated since these learning modes are conducted without interaction between the learners and teachers. Lastly, as learners are compelled to continue their education from their own homes, they face an entirely different set of distractions that may hinder them from completing the required task and activities. Thus, each school in the Philippines faces different challenges with learner engagement. Still, for some educators who already facilitated distance learning, it comes in handy in preparing for the new normal of learning. 
In support of the goal of the Department of Education in addressing the challenges experienced by the pupils. The researchers would like to study how the pupils accept the challenges they experienced in the new normal and how they cope with those challenges in implementing distance learning that can help them improve their performance. These were the researchers' reasons to conduct the study to support and help pupils with difficulty in distance learning. Furthermore, it attempted to investigate the pupils' challenges and coping mechanisms in implementing distance learning modality concerning the performance of grade 5 pupils at Bagong Pag-Asa Elementary School.

The COVID-19 pandemic has drastic changes in education (De Villa et al., 2020; del Castillo et al., 2020). Part of it is the shift from face-to-face classes to different learning modalities, which include distance learning. Since education is believed to continue despite the circumstances, teachers started to prepare for modular and online distance learning. Teaching is possible, but has challenges as well. Hence, this phenomenological research explored the lived experiences of secondary teachers in the Division of San Pablo City in the pre-implementation of distance learning in the new normal. The participants were selected through purposive sampling and underwent one-on-one actual in-depth interviews through video conferences. The documented interviews were transcribed and coded. Categories were clustered; then, emerging themes were derived. Results identified three core themes related to preparation: gathering resources and establishing practices, profiling learners, and capacity building for continuous learning and development. In addition, there are three core themes related to challenges such as complexity of assessment, difficulty in instructional delivery, and the digital divide. And five core themes related to coping mechanisms include positive well-being, time management, openness to change, peer mentoring, and collaboration. Findings revealed that as education migrates to a New Normal, teachers make necessary preparations to equip themselves with distance learning.

Though they face challenges that may hamper their work, they still manage to cope with the new normal to continue their tasks. Therefore, the higher offices and school authorities should work with teachers at the pre-implementation of distance learning to address their needs in resources and training to effectively facilitate quality education for students.

Kwaah (2017) added that Globally, the traditional higher education delivery system, which has a classroom setting with students and lecturer interactions, has been challenged by innovations in educational delivery mechanisms. The study results showed that 'academic workload,' 'high frequency of examinations,' 'financial problems, family/marriage problems' were the major causes of stress among the students. The study also found some statistically significant differences between married and unmarried students, with married students feeling more stressed with 'financial problems' and 'family/marriage problems' than unmarried students. Students used multiple strategies, mainly praying/meditating, self-distracting activities such as watching TV, and listening to music to cope with stress. Other important stressors coping strategies were emotional and instrumental support from family, friends, and lecturers.

The study recommended that the counseling unit at the College of Distance Education of UCC organize frequent stress management programs for students and assign academic counselors to students. Similarly, Moir (2020) examined how three coping strategies could support students in Further Education who have difficulties expressing themselves and some self-harm students. The first strategy is the ABC Chain Analysis which encourages students who either Self-harm or had emotional outbursts to reflect on how to respond differently. The second strategy is a Happy Bag and Music. Students identified objects and downloaded music that reminded them of happier times. The third strategy: The Safety Plan, is a detailed, individual plan of safe places, people, and experiences for the participants. Data collection involved: learning journals, questionnaires, observations, and interviews. Using different data collection techniques allowed the students varied opportunities to express their opinions. Peer pressure and relationship difficulties mostly affected the group. Findings concluded that all three strategies were effective methods to support students, with the Happy Bag proving the most popular.

Arguably, the Chain Analysis and Safety Plan are more cognitive than practical and may be more effective for 
students who do not have learning difficulties, but further research would be required. Nevertheless, the group reported that being able to empower themselves to cope with difficult situations was very helpful. Furthermore, these findings have proved useful for colleagues' professional development in supporting students with these issues.

Further, Pierceall (2020) determines the degree of stress perceived by students at two community colleges in southern Illinois. The Perceived Stress Scale was used to gather data from 212 students enrolled in regularly scheduled psychology classes. Of the students, $75 \%$ were in a moderate stress category, $12 \%$ in a high-stress category, and $13 \%$ in a low-stress category. Women students were more stressed than men; there were no statistically significant differences between traditional and nontraditional students. The most often used activities to cope with stress included talking to family and friends, leisure activities, and exercising. Less desirable coping strategies were drinking alcohol, smoking, and using illegal drugs. Suggestions for community college personnel to use in assisting students in coping with stress are discussed.

\subsection{Significance of the study}

The following individuals benefited from this study:

School Administrators and Academic Heads. The study will guide the school administrators to attend to the needs of grade 5 pupils, which can be the basis in developing and crafting appropriate instructional tools, materials, platforms, and methodologies suited to every learner's interest and needs.

Teachers. This will serve as their guide in the teaching process of the new normal that can help improve the pupils' performance.

Parents. They may realize the importance of the role they play involving themselves in the learning and development of their child.

Pupils. They may get more information on how they can maximize their time in answering the given task and guide them in coping with all the challenges they encountered in distance learning.

Researchers. The researchers may pursue parallel studies. They may also conduct a more in-depth investigation on the effectiveness of the distance learning program in other institutions.

\section{Research Methodology}

This chapter presents the subject of the study or the participants, data gathering methods, and data analysis plan.

Sampling - The respondents of the study were the forty-five (45) Grade Five pupils who are enrolled in the distance learning modality of Bagong Pag - Asa Elementary School. The researchers utilized non-probability sampling, specifically the purposive sampling technique, to determine the section that served as the subject of the study.

Data Collection - The study used the mixed method of research, specifically the sequential transformative design. In the study, the descriptive correlation was also used to determine the relationship between the extent of challenges in implementing distance learning modality and the performance of Grade 5 pupils. More so, the researchers utilized the researcher-made instrument.

The data for this research were collected from instruments used. The following range of scores to be used and the corresponding verbal interpretations on the level of pupils' challenges in the implementation of distance learning modality are as follows: 
Pupils' challenges and coping mechanism in distance learning modality and its relation to their performance

$\begin{array}{ccl}\text { Score } & \text { Range } & \text { Verbal Interpretation } \\ 4 & 3.51-4.00 & \text { Highly Challenged (HC) } \\ 3 & 2.51-3.50 & \text { Challenged (C) } \\ 2 & 1.51-2.50 & \text { Moderately Challenged (MC) } \\ 1 & 1.00-1.50 & \text { Less Challenged (LC) }\end{array}$

In addition to the researcher-made questionnaire, the registration method was used to collect data about the academic grades of the pupils as revealed by the average grade in the first quarter. These data were collected from the adviser of the pupils. To interpret the performance of pupils as revealed by their average grade in the first quarter, the following ranges and interpretations were utilized:
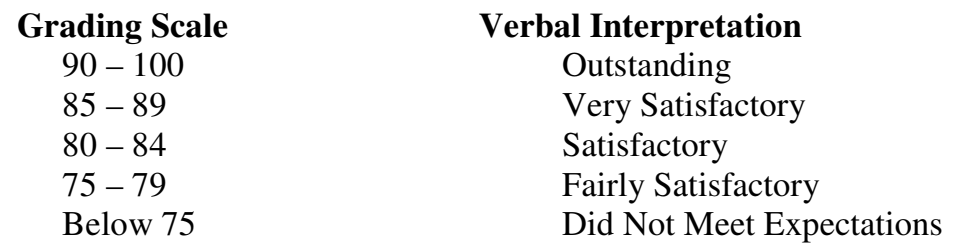

The highly proficient teachers checked the survey questionnaire used to gather initial comments and suggestions to improve the questionnaire checklist. Then, after revision of the instrument had been made, the researcher's made the experts validated questionnaire checklist with a reasonable background in test construction and on the topic to comment on its content to finalize the items to be included in the instrument. In qualitative research, the researchers conducted a series of interviews on the coping mechanisms and strategies of the pupils to overcome the challenges and problems they encountered in the implementation of distance learning. Upon completion of the content validation form, the researchers sought permission from the offices of the principal and public schools district supervisor to administer the instrument to the respondents. Then, immediate retrieval of the instrument was done.

\subsection{Data Analysis}

The following are the steps in analyzing the result of the study.

$>\quad$ To determine the level of pupils' challenges in implementing distance learning modality in terms of individual, instructional, and school-related challenges, mean was utilized.

$>\quad$ To determine the level of performance of grade 5 pupils as revealed by their average grade in the first quarter, frequency and percentage distribution were applied.

$>\quad$ To find out if there is a significant relationship between the level of pupils' challenges in implementing modular learning modality and the performance of Grade 5 pupils as revealed by their average grade in the first quarter, Pearson 'r' correlation was utilized.

$>\quad$ A qualitative approach was utilized to determine the coping mechanism of grade 5 pupils concerning the implementation of distance learning.

$>\quad$ In addition, the results gathered from the instrument and the performance of the pupils were treated and interpreted using the appropriate statistical tools mentioned above.

\section{Findings and Discussion}

This page presents the analysis and interpretation of data gathered to answer the problems stated in the previous chapter. What is the level of pupils' challenges in the implementation of distance learning modality in terms of Individual related challenges, Instructional related challenges, and School-related challenges? 


\section{Table 1}

Challenges in implementation of distance learning modality concerning individual related challenges

\begin{tabular}{|c|c|c|}
\hline Individual Related Challenges & Mean & Verbal Interpretation \\
\hline Lack of sufficient time for study. & 3.67 & Highly Challenged \\
\hline Lack of support from family, friends, etc. & 3.44 & Challenged \\
\hline Lack of knowledge in answering the activities in the module & 3.49 & Challenged \\
\hline The unfavorable home learning environment & 3.53 & Highly Challenged \\
\hline Difficulties in learning technically demanding learning material & 3.51 & Highly Challenged \\
\hline Overall & 3.52 & Highly Challenged \\
\hline
\end{tabular}

It can be gleaned from the table that the overall mean of pupils' challenges in implementing distance learning modality in terms of individual-related challenges is 3.52 verbally interpreted as Highly Challenged. It means that the pupils have difficulty managing their time for studying their lesson and have an issue regarding their learning environment. It can also imply that pupils need full parental support in doing their activities in the module. The findings suggest that pupils should give focus on time management for their studies.

Table 2

Challenges in the implementation of distance learning modality concerning instructional related challenges

\begin{tabular}{lcc}
\hline \multicolumn{1}{c}{ Instructional Related Challenges } & Mean & Verbal Interpretation \\
\hline Delayed and ineffective feedback from my teachers. & 3.58 & Highly Challenged \\
Lack of my teacher's contact and support & 3.49 & Challenged \\
Difficulty in understanding the instruction given by my teacher. & 3.47 & Challenged \\
Difficulty in getting my module at school & 3.44 & Challenged \\
Unhelpful class information and lack of direction & 3.49 & Challenged \\
$\quad$ Overall & 3.49 & Challenged \\
\hline
\end{tabular}

It can be manifested from the table that the overall mean of pupils' challenges in implementing distance learning modality in terms of instructional-related challenges is 3.49 verbally interpreted as Challenged. It means that the pupils have a problem with instructions from their teachers on what activities to be done. They also have difficulty in understanding the instructions in the module due to lack of communication. It implies that pupils have difficulty in understanding the instructions from their teachers. The findings suggest that teachers should give enough time to answer the pupils' queries and assist.

Table 3

Challenges in the implementation of distance learning modality concerning school related challenges

\begin{tabular}{|c|c|c|}
\hline School-Related Challenges & Mean & Verbal Interpretation \\
\hline Delayed distribution of the module at school. & 3.56 & Highly Challenged \\
\hline Lack of an effective school network of technical assistance. & 3.51 & Highly Challenged \\
\hline It was delayed in giving important information and activities to be done. & 3.51 & Highly Challenged \\
\hline Lack of responsiveness from my teachers. & 3.53 & Highly Challenged \\
\hline Lack of appropriate advice provided by my teachers and classmates. & 3.51 & Highly Challenged \\
\hline 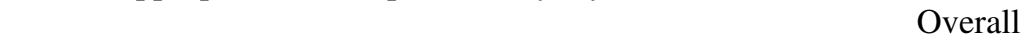 & 3.52 & Highly Challenged \\
\hline
\end{tabular}

It can be exhibited from the table that the overall mean of pupils' challenges in implementing distance learning modality in terms of school-related challenges is 3.52 verbally interpreted as Highly Challenged. It means that the pupils have difficulty getting their modules at school and lack communication with their teachers. Furthermore, it implies that pupils have a problem distributing the modules and submitting the activities at school due to the pandemic they are experiencing. Therefore, the findings suggest that schools should have an appropriate plan and strategies in distributing the module to their learners. 
Pupils' challenges and coping mechanism in distance learning modality and its relation to their performance

Table 4

Level of performance of grade five pupils as revealed by their average grade in first quarter

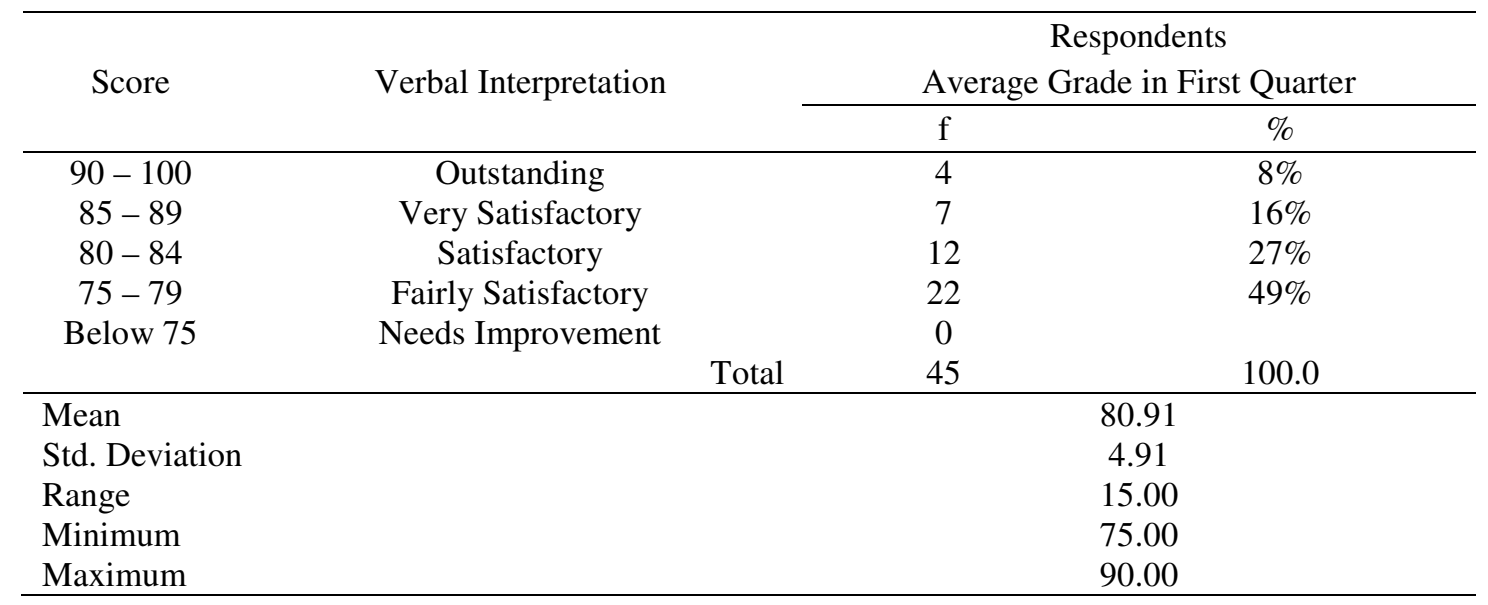

It can be gleaned from the table that most learners obtained a Fairly Satisfactory rating, followed by twelve (12) learners who have a satisfactory rating. Seven (7) learners got a very satisfactory rating. Meanwhile, four of them garnered an outstanding rating. It implies that learners slightly performed in their first quarter due to the challenges that they encountered. The findings suggest that the pupils should understand the teachers' instruction to answer the module accurately to increase their performance.

\section{Table 5}

Relationship between pupils' challenges and the level of performance

\begin{tabular}{|c|c|c|c|c|c|}
\hline $\begin{array}{l}\text { The extent of Implementing } \\
\text { the Modular Approach }\end{array}$ & $\begin{array}{c}\text { Level of } \\
\text { Performance }\end{array}$ & Computed $\mathrm{r}$ & Sig & $\begin{array}{l}\text { Decision } \\
\text { on Ho }\end{array}$ & Interpretation \\
\hline $\begin{array}{c}\text { Individual Related } \\
\text { Challenges }\end{array}$ & $\begin{array}{l}\text { Average Grade } \\
\text { (First Quarter) }\end{array}$ & -.071 & .642 & $\begin{array}{l}\text { Failed to } \\
\text { Reject }\end{array}$ & Not Significant \\
\hline $\begin{array}{c}\text { Instructional Related } \\
\text { Challenges }\end{array}$ & $\begin{array}{l}\text { Average Grade } \\
\text { (First Quarter) }\end{array}$ & -.053 & .731 & $\begin{array}{l}\text { Failed to } \\
\text { Reject }\end{array}$ & Not Significant \\
\hline School-Related Challenges & $\begin{array}{l}\text { Average Grade } \\
\text { (First Quarter) }\end{array}$ & -.035 & .820 & $\begin{array}{c}\text { Failed to } \\
\text { Reject }\end{array}$ & Not Significant \\
\hline
\end{tabular}

The table reveals that it was statistically found out that there is no significant relationship between the level of pupils' challenges in the implementation of modular learning modality and the performance of Grade 5 pupils ass revealed by their average grade in the first quarter since the obtained $p$-value of 0.00 does not exceed at 0.05 level of significance. Thus the null hypothesis is failed to reject. It simply implies that pupils' challenges in implementing modular learning modalities did not significantly correlate to their performance. Nevertheless, the findings suggest that pupils should do their best in understanding the instruction in the module to improve their performance.

\section{Conclusion}

Based on the analysis and interpretation of the data, the following findings are summarized: The pupils are highly challenged in implementing modular learning modality with an overall mean of 3.51 in terms of individual and school-related challenges. They are also challenged in terms of related instructional challenges wherein the pupils have difficulty understanding the instruction in the module due to lack of communication. It implies that pupils have difficulty in understanding the instructions from their teachers. However, the majority of the learners obtained a Fairly Satisfactory rating. There is no significant relationship between the level of pupils' challenges in the implementation of modular learning modality and the performance of Grade 5 pupils as revealed by their average grade in the first quarter since the obtained $p$-value of 0.00 does not exceed at 0.05 level of significance. Thus the null hypothesis is failed to reject. It simply implies that pupils' challenges in 
Garcia, M. G.

implementing modular learning modalities did not significantly correlate to their performance.

According to the pupils, their coping mechanism in the implementation of modular learning modality is the following: Boosting self-confidence by encouraging each other; positive outlook in addressing the challenges in the new normal; time management is a must to accomplish the activities on time; prioritizing in answering the learning activities even late at night; openness to change, and to seek help and assistance from their teachers and classmates.

\section{References}

De Villa, J. A., \& Manalo, F. K. B. (2020). Secondary teachers' preparation, challenges, and coping mechanism in the pre-implementation of distance learning in the new normal. IOER International Multidisciplinary Research Journal, 2(3).

del Castillo, F. A., \& del Castillo, C. D. B. (2020). Lessons from COVID19: Advocacy toward the vulnerable. Journal of Public Health, 42(4), 869-870. https://doi.org/10.1093/pubmed/fdaa121

Douglas, I. (2020). Measuring student's participation and report. Florida State University, Tallahassee, Florida.

Kwaah, C. Y. (2017). Stress and coping strategies among distance education students at the university of cape coast, Ghana. Turkish Online Journal of Distance Education, 18(3). https://doi.org/10.17718/tojde.328942

Moir, A. (2020). Coping strategies for students. The University of Aberdeen.

Onojetah, S. O. (2020). Challenges and coping strategies for enhancing the effectiveness of distance learning in achieving business education objectives. Journal of Educational and Social Research, 10(3). https://doi.org/10.36941/jesr-2020-0055

Pierceall, E. A. (2020). Stress and coping strategies among community college students. Community College Journal of Research and Practice, 31(9), 703-712. https://doi.org/10.1080/10668920600866579 